\title{
BMJ Open Rheumatoid factor and anti-CCP do not predict progressive joint damage in patients with early rheumatoid arthritis treated with prednisolone: a randomised study
}

\author{
Ingiäld Hafström, ${ }^{1}$ Inga-Lill Engvall, ${ }^{1}$ Johan Rönnelid, ${ }^{2}$ Annelies Boonen, ${ }^{3}$ \\ Désirée van der Heijde, ${ }^{4}$ Björn Svensson, ${ }^{5}$ on behalf of the BARFOT study group
}

To cite: Hafström I,

Engvall I-L, Rönnelid J, et al. Rheumatoid factor and antiCCP do not predict progressive joint damage in patients with early rheumatoid arthritis treated with prednisolone: a randomised study. BMJ Open 2014;4:e005246. doi:10.1136/bmjopen-2014005246

- Prepublication history for this paper is available online. To view these files please visit the journal online (http://dx.doi.org/10.1136/ bmjopen-2014-005246).

Received 12 March 2014 Revised 16 June 2014 Accepted 4 July 2014

CrossMark

For numbered affiliations see end of article.

Correspondence to Dr Ingiäld Hafström; ingiald.hafstrom@karolinska.se

\section{ABSTRACT}

Objective: To analyse if predictors of radiographic progression differ between patients treated with or without prednisolone in early rheumatoid arthritis (RA). Radiographs of hands and feet were assessed using the modified Sharp/van der Heijde score and radiographic progression was defined as an increase in the total Sharp score above 5.8 (the smallest detectable change).

Design: Prospective, randomised study of patients with early RA.

Setting: Secondary level of care; six participating centres from southern Sweden; both urban and rural populations.

Participants: In all, 225 patients, $64 \%$ women, with a diagnosis of RA according to the American College of Rheumatology criteria, were included if they were between 18 and 80 years of age and had a disease duration of less than 1 year.

Intervention: The patients were randomised to $7.5 \mathrm{mg}$ prednisolone daily for 2 years (P-group; $\mathrm{n}=108$ ) or no prednisolone (NoP-group; $n=117$ ) when they started with their first disease-modifying anti-rheumatic drug and were prospectively followed for 2 years.

Results: The frequency of patients with radiographic progression after 2 years was $26 \%$ in the P-group and $39 \%$ in the NoP-group ( $p=0.033$ ). Relevant interactions between treatment and rheumatoid factor (RF) $(p=0.061)$ and between treatment and anti-cyclic citrullinated peptide 2 (anti-CCP) ( $p=0.096)$ were found. RF and anti-CCP independently predicted radiographic progression only in the NoP-group, $\mathrm{OR}$ (95\% Cl) 9.4 (2.5 to 35.2), $\mathrm{p}=0.001$ and $\mathrm{OR}(95 \% \mathrm{Cl})$ 8.7 (2.5 to 31.3 ), $p=0.001$, respectively.

Conclusions: The presence of RF and anti-CCP predicted radiographic progression in patients not treated with prednisolone but failed to predict progression in patients treated with this drug. The data suggest that early treatment with prednisolone may modulate not only inflammation but also autoimmunity-associated pathogenetic mechanisms.

Trial registration number: ISRCTN20612367.

\section{Strengths and limitations of this study}

A strength of the study is the prospective design with randomisation of patients with early rheumatoid arthritis to treatment with low-dose prednisolone or no prednisolone together with diseasemodifying anti-rheumatic drug for 2 years.

- Another strength is that most patients followed the treatment they were randomised to.

- The main limitation is the rather small number of patients in each subgroup, which may reduce statistical power.

\section{INTRODUCTION}

Recent treatment strategies in early rheumatoid arthritis (RA) have considerably improved outcome. Nevertheless, most clinical trials as well as clinical practice show significant subgroups of patients who fail to respond and develop progressive joint damage.

In the BARFOT low-dose prednisolone study on 250 patients with early RA $(<1$ year disease duration), joint progression was less frequent after 2 years in the group of patients who in addition to disease-modifying anti-rheumatic drugs (DMARDs) got prednisolone $7.5 \mathrm{mg}$ daily compared to those treated with DMARDs alone. ${ }^{1}$ Despite this achievement, some patients in the prednisolone group deteriorated radiographically while some in the non-prednisolone group did not.

We therefore wanted to study if predictors of radiographic progression differed between patients treated with or without prednisolone in early RA.

\section{METHODS}

\section{Patients}

The patients had all participated in the BARFOT low-dose prednisolone study in which radiographic progression was the 
primary outcome. ${ }^{1}$ DMARDs were chosen by the treating physicians with the goal of achieving remission, defined as a Disease Activity Score (DAS28) <2.6. In addition, the patients were randomised to prednisolone, $7.5 \mathrm{mg} /$ day (P-group, $\mathrm{n}=119$ ), or no prednisolone (NoP-group, $\mathrm{n}=131$ ) for 2 years.

The present study population consisted of $225(90 \%$ of the randomised) patients who had radiographs of hands and feet at both baseline and the 2-year follow-up. Of these, 108 patients were in the P-group and 117 in the NoP-group.

All patients gave their informed consent and the ethics committees approved the study, which was performed in accordance with the Helsinki Declaration.

\section{Radiographic assessment}

Radiographs were scored for erosions, joint space narrowing and total Sharp scores (TSS) with known time sequence using the van der Heijde modification of the Sharp score by two readers. ${ }^{2}$ The smallest detectable change, based on interobserver data, was calculated to be $5.8,{ }^{1}$ admitting radiographic progressors to be defined as having a TSS $>5.8$.

\section{Disease activity and physical function}

Disease activity was assessed by DAS28. ${ }^{3}$ The Swedish version of the Stanford Health Assessment Questionnaire (HAQ) was used to measure daily life function. ${ }^{4}$

\section{Laboratory analyses}

Plasma and serum samples were stored at $-70^{\circ} \mathrm{C}$ until assay. IgM rheumatoid factor (RF) and anti-cyclic citrullinated peptide 2 (anti-CCP) were analysed using enzyme immunoassay (Phadia 250; Thermofisher AB, Uppsala, Sweden). Levels of $\geq 5$ international units (IU) $/ \mathrm{mL}$ (IgM $\mathrm{RF}$ ) and $\geq 7$ arbitrary units (AU) $/ \mathrm{mL}$ (anti-CCP) were regarded as positive. Samples from individual patients were analysed in parallel. When 100 healthy blood donor controls were analysed in the same laboratory, 4 were IgM RF positive and none were anti-CCP positive, corresponding to $96 \%$ and $100 \%$ specificity, respectively.

Procollagen type I N-terminal propeptide (P1NP; marker of bone formation), C-terminal telopeptide crosslaps (CTX-1) and C-terminal telopeptides of type I collagen (1CTP; both markers of bone degradation) were analysed as described earlier. ${ }^{5}$

\section{Statistics}

The SPSS V.21.0 statistical software was used. To test differences between groups, the Mann-Whitney U test or unpaired $t$ test was used for continuous variables, whereas the Wilcoxon matched pairs test was used for paired comparisons and the $\chi^{2}$ test for proportions.

To identify predictors of radiographic progression, univariate analyses of baseline clinical and demographic variables were performed. Variables with a $p$ value less than 0.1 were entered into multivariate logistic regression models with radiographic progression as the dependent variable. Prediction analyses in subgroups were justified by interaction analyses of treatment (prednisolone or no prednisolone) and anti-CCP (or RF) plus the interaction term between them (relevant interaction $\mathrm{p}<0.1$ ).

\section{RESULTS}

\section{Radiographic progression}

After 2 years, the frequency of patients with radiographic progression (progressors) was $26 \%$ in the P-group and $39 \%$ in the NoP-group, $\mathrm{p}=0.033$.

\section{Baseline characteristics and associations between baseline variables and radiographic progression}

Demographic and clinical characteristics at baseline in patients with and without progression of joint damage after 2 years are shown in table 1 . Univariate analyses per treatment group showed that in the P-group progressors had significantly more swollen joints and higher TSS than non-progressors, whereas in the NoP-group the presence of RF and anti-CCP as well as elevated C reactive protein (CRP) and TSS was associated with radiographic progression. Concentrations of P1NP, CTX-1 and 1CTP did not differ significantly between progressors and non-progressors, irrespective of prednisolone treatment.

\section{Prednisolone and concomitant treatment}

In the P-group, some patients reduced the prednisolone dose and eight stopped treatment. In the NoP-group, six patients started prednisolone treatment during the study period. DMARD treatment (mostly methotrexate and sulfasalazine) was given to all patients and did not differ between progressors and non-progressors either in the P-group or in the NoP-group during the first 3 months.

\section{Prediction of radiographic progression}

In addition to RF and anti-CCP, baseline swollen joint count, TSS, erythrocyte sedimentation rate, CRP and HAQ were univariately associated with radiographic progression $(p<0.1)$ and were entered into multivariate logistic models, in which RF, anti-CCP and TSS proved to be independent predictors.

Prediction analyses in subgroups were justified by interaction analyses (relevant interaction $\mathrm{p}<0.1$ ). Thus, relevant interactions between treatment and $\mathrm{RF}$ $(\mathrm{p}=0.061)$ and between treatment and anti-CCP ( $p=0.096$ ) were found. RF and anti-CCP independently predicted radiographic progression only in the NoPgroup, OR (95\% CI) 9.4 (2.5 to 35.2 ), $\mathrm{p}=0.001$ and $\mathrm{OR}$ $(95 \%$ CI $) 8.7$ (2.5 to 31.3$), \mathrm{p}=0.001$, respectively.

\section{Change in RF and anti-CCP during 2 years follow-up}

In both treatment groups, most patients retained their $\mathrm{RF}$ and anti-CCP status (pos./neg.) during the two study years: for the P-group, $82.3 \%$ and $87.5 \%$, respectively and for the NoP-group, $88.9 \%$ and $98 \%$, respectively. 
Table 1 Demographic and clinical characteristics at baseline separated into patients randomised to prednisolone (P-group, $\mathrm{n}=108$ ) and no prednisolone (NoP-group, $\mathrm{n}=117$ ) and further separated into those who after 2 years had progression in TSS $>5.8$ or not, progressors and non- progressors, respectively

\begin{tabular}{|c|c|c|c|c|c|c|}
\hline \multirow[b]{2}{*}{ Baseline characteristics } & \multicolumn{3}{|l|}{ P-group } & \multicolumn{3}{|l|}{ NoP-group } \\
\hline & $\begin{array}{l}\text { Progressors } \\
n=28\end{array}$ & $\begin{array}{l}\text { Non-progressors } \\
n=80\end{array}$ & p Value & $\begin{array}{l}\text { Progressors } \\
n=46\end{array}$ & $\begin{array}{l}\text { Non-progressors } \\
n=71\end{array}$ & p Value \\
\hline Age, years & $50(13)$ & $52(15)$ & 0.57 & $58(13)$ & $58(13)$ & 0.89 \\
\hline Women, n (\%) & $17(61)$ & $52(65)$ & 0.68 & $29(63)$ & $46(65)$ & 0.85 \\
\hline \multicolumn{7}{|l|}{ Smokers } \\
\hline Ever, \% & 78.6 & 61.3 & 0.10 & 63.0 & 60.0 & 0.74 \\
\hline Never, \% & 21.4 & 38.8 & & 37.0 & 40.0 & \\
\hline Disease duration, months & $7(3)$ & $6(4)$ & 0.83 & $6(3)$ & $6(3)$ & 0.22 \\
\hline RF pos., n (\%) & $20(74.1)$ & $38(54.3)$ & 0.075 & $33(86.8)$ & $30(48.4)$ & 0.001 \\
\hline Anti-CCP pos., n (\%) & $20(74.1)$ & $41(58.6)$ & 0.157 & 31 (81.6) & $28(45.2)$ & 0.001 \\
\hline DAS28 & $5.33(1.34)$ & $5.23(1.02)$ & 0.69 & $5.44(1.06)$ & $5.45(0.98)$ & 0.94 \\
\hline $\mathrm{ESR}, \mathrm{mm}$ & $41(24)$ & $36(26)$ & 0.38 & $43(23)$ & $34(25)$ & 0.06 \\
\hline Swollen joints, $n$ & $13(5)$ & $11(5)$ & 0.029 & $11(6)$ & $11(5)$ & 0.82 \\
\hline Tender joints, $n$ & $8(7)$ & $7(5)$ & 0.88 & $8(7)$ & $9(6)$ & 0.26 \\
\hline General health, VAS, mm & $39(29)$ & $47(21)$ & 0.14 & $43(23)$ & $48(24)$ & 0.23 \\
\hline $\mathrm{CRP}, \mathrm{mg} / \mathrm{L}$ & $38(31)$ & $30(30)$ & $0.08^{*}$ & $43(38)$ & $31(37)$ & $0.012^{\star}$ \\
\hline Pain, VAS, mm & $44(25)$ & $48(22)$ & 0.38 & $47(20)$ & $50(22)$ & 0.39 \\
\hline $\mathrm{HAQ}(0-3)$ & $0.94(0.71)$ & $1.01(0.53)$ & 0.56 & $1.13(0.58)$ & $0.9(69)$ & 0.07 \\
\hline TSS & $5.37(6.11)$ & $3.67(10.16)$ & $0.033^{*}$ & $8.50(13.13)$ & $2.53(5.53)$ & $0.001 \dagger$ \\
\hline P1NP & $33(16)$ & $22(9)$ & 0.074 & $48(12)$ & $49(21)$ & 0.82 \\
\hline CTX-1 & $0.26(0.14)$ & $5.1(0.15)$ & 0.15 & $0.35(0.18)$ & $0.33(0.19)$ & 0.82 \\
\hline $1 \mathrm{CTP}$ & $4.1(1.8)$ & $5.9(7.7)$ & 0.54 & $5.1(1.4)$ & $5.2(2.6)$ & 0.93 \\
\hline
\end{tabular}

Statistically significant values are shown in bold typeface.

$\mathrm{p}$ Values represent differences between progressors and no progressors. Values are mean (SD). Swollen and tender joints were calculated on 28 joints.

*Mann-Whitney $U$ test.

CCP, cyclic citrullinated peptide 2; CRP, C reactive protein; 1CTP, C-terminal telopeptides of type I collagen; CTX-1, C-terminal telopeptide crosslaps; DAS28, Disease Activity Score in 28 joints; ESR, erythrocyte sedimentation rate; HAQ, Health Assessment Questionnaire; P1NP, procollagen type I N-terminal propeptide; RF, rheumatoid factor; TSS, total Sharp score.

Some patients, however, reversed from $\mathrm{RF}$ and/or anti-CCP positivity to negativity: in the P-group $15.6 \%$ and $9.4 \%$, respectively, and in the No-P-group $9.9 \%$ and $2.0 \%$, respectively. More patients lost than acquired seropositivity.

RF and anti-CCP levels among seropositive patients did not differ between treatment groups at baseline or at 2 years, but in both treatment groups there were significant reductions in both autoantibody levels during the study period (table 2). When calculated only on those patients who were compliant with the randomisation and dose of prednisolone, the P-group had a larger reduction of anti-CCP than the NoP-group, $\mathrm{p}=0.028$ (table 2).

\section{DISCUSSION}

The present study was undertaken to analyse if predictors for radiographic progression differed between patients with early RA treated with or without

Table 2 Levels of RF and anti-CCP (median (IQR)) in patients positive for one or both of these antibodies in the two treatment groups

\begin{tabular}{|c|c|c|c|c|}
\hline & P-group $(n=97)$ & $\begin{array}{l}\text { NoP-group } \\
(n=100)\end{array}$ & $\begin{array}{l}\text { p Value } \\
\text { between } \\
\text { groups }\end{array}$ & $\begin{array}{l}\text { p Value between groups, } \\
\text { only patients with dose } \\
\text { according to protocol } \\
\text { (77 vs } 94 \text { ) }\end{array}$ \\
\hline RF, baseline (IU/mL) & $12.0(1.3-58.0)$ & $21.5(1.9-80.5)$ & 0.39 & 0.91 \\
\hline Anti-CCP, baseline (AU/mL) & $28.0(3.4-367.0)$ & $43.5(2.5-384.5)$ & 0.63 & 0.38 \\
\hline $\mathrm{RF}, 2$ years & $4.1(0.7-28.0)$ & $9.5(1.00-52.0)$ & 0.14 & 0.41 \\
\hline Anti-CCP, 2 years & $13.0(2.3-141.0)$ & $24.0(2.1-446.0)$ & 0.70 & 1.00 \\
\hline$\Delta \mathrm{RF}, 0-2$ years & $-1.1(-20.3-0.20)^{\star *}$ & $-1.5(-34.0-0)^{* *}$ & 0.63 & 0.69 \\
\hline$\Delta$ Anti-CCP, $0-2$ years & $-1.9(-55.4 \text { to }-0.10)^{\star \star}$ & $-0.3(-88.0-0.5)^{\star}$ & 0.14 & 0.028 \\
\hline
\end{tabular}

Statistically significant values are shown in bold typeface.

${ }^{*} \mathrm{p}<0.05,{ }^{\star *} \mathrm{p}<0.001$ (Wilcoxon matched pairs test).CCP, cyclic citrullinated peptide 2; RF, rheumatoid factor. 
prednisolone, in combination with DMARDs during the first 2 years after diagnosis. The main finding was that $\mathrm{RF}$ and anti-CCP predicted radiographic progression only in the group not treated with prednisolone.

The presence of RF and antibodies against citrullinated proteins/peptides (ACPA) has been found to predict the development of RA and also the severity of the disease, suggesting a possible pathogenic role for these autoantibodies. ${ }^{6-8}$ If so, the present finding that RF-positivity and anti-CCP-positivity did not predict radiographic progression in prednisolone-treated patients may imply that prednisolone affects the pathogenic mechanisms associated with these antibodies in early RA. This possibility is in line with a role for RF in joint damage progression beyond its direct effect on disease activity. ${ }^{9}$ Interestingly, such effects of RF, independent of disease activity, have been shown to be significantly associated only with progression of the erosion score, but not with the joint space narrowing score. ${ }^{9}$ Similarly, we have reported earlier that the hampering effect of prednisolone on radiographic progression was valid only for erosions. ${ }^{10}$

The lack of association between autoantibody status and radiographic progression in prednisolone-treated patients is consistent with similar findings in patients treated with some biological agents. ${ }^{11}{ }^{12}$ It is further in line with the findings in the BEST study where the association of ACPA status with joint damage progression was significantly more pronounced in patients treated with initial methotrexate monotherapy compared with those getting combination therapy with prednisolone or antitumour necrosis factor agents. ${ }^{13}$ One explanation might be that early and intensive reduction of inflammation, also found here in the P-group, may suppress a strong autoimmune response. ${ }^{14}$

Such an explanation to the fact that the autoantibodies at baseline did not predict radiographic progression in the P-group is supported by the finding that more patients in this group reverted from seropositivity to negativity. In a recent study by Barra $e t a l^{15}$ on early inflammatory arthritis, seroreversion occurred at rates similar to those in the present study without any influence on the prediction of outcome. However, in another early polyarthritis cohort, the prognostic significance of initial RF and anti-CCP positivity was influenced by seroreversion of these antibodies. ${ }^{16}$

Not only antibody status but also serum level changes might be of importance in the prediction of outcome. Here we found that the levels of RF and anti-CCP decreased in both treatment groups. The decrease of anti-CCP was significantly more profound in the P-group when the calculation was based on the patients who strictly followed randomisation and dose. We suggest that such a subgroup analysis is important to find specific effects of prednisolone. Reports on the predictive value of changes in autoantibody levels are limited, but one study on early RA reports that changes in RF and ACPA levels were not associated with radiographic outcome. ${ }^{17}$ In established RA, RF and ACPA level reductions are reported to be closely linked to treatment-associated improvements. ${ }^{18}$ However, it remains unknown whether such reductions are associated with hampered structural changes.

In conclusion, the presence of RF and anti-CCP did not predict radiographic progression in patients treated with prednisolone in contrast to prednisolone-naive patients. The data imply that early treatment with prednisolone may modulate not only inflammation but also autoimmunity-associated pathogenetic mechanisms. The clinical implication would be that the unfavourable prognosis associated with RF-positivity and anti-CCP-positivity can be relieved by prednisolone treatment.

\section{Author affiliations}

${ }^{1}$ Rheumatology Unit, Karolinska Institutet at Karolinska University Hospital Huddinge, Stockholm, Sweden

${ }^{2}$ Department of Immunology, Genetics and Pathology, Uppsala University, Uppsala, Sweden

${ }^{3}$ Department of Internal Medicine, Division of Rheumatology, University Hospital, and CAPHRI Research Institute Maastricht, Maastricht,

The Netherlands

${ }^{4}$ Department of Rheumatology, Leiden University Medical Center, Leiden, The Netherlands

${ }^{5}$ Department of Clinical Sciences, Section of Rheumatology, Lund University, Lund, Sweden.

Acknowledgements We thank research nurse Margareta Wörnert for excellent assistance, MD Kristina Albertsson for scoring radiographs and the following members of the BARFOT study group: Maria Andersson, Kristina Forslind, Catharina Keller, Ido Leden, Bengt Lindell, Ingemar Petersson, Christopher Schaufelberger, Annika Teleman and Jan Theander.

Contributors $\mathrm{IH}, \mathrm{AB}, \mathrm{DvdH}$ and $\mathrm{BS}$ were involved in the original planning of the low-dose prednisolone study and interpretation of data. $\mathrm{IH}$ was responsible for data acquisition and preparing the manuscript, $A B$ for scoring the radiographs, and BS and DvdH for statistical analyses. I-LE was involved in the statistical analyses and JR performed the analyses of RF and anti-CCP. All authors read and approved the manuscript.

Funding This work was supported by grants from the Swedish Rheumatism Association, King Gustav V 80-year Foundation, the Swedish Research Council and through the regional agreement on medical training and clinical research (ALF) between the Stockholm County Council and Karolinska Institutet.

\section{Competing interests None.}

Ethics approval Lund University, Gothenburg University, Karolinska Institutet and Linköping University.

Provenance and peer review Not commissioned; externally peer reviewed.

Data sharing statement No additional data are available.

Open Access This is an Open Access article distributed in accordance with the Creative Commons Attribution Non Commercial (CC BY-NC 4.0) license, which permits others to distribute, remix, adapt, build upon this work noncommercially, and license their derivative works on different terms, provided the original work is properly cited and the use is non-commercial. See: http:// creativecommons.org/licenses/by-nc/4.0/

\section{REFERENCES}

1. Svensson B, Boonen A, Albertsson K, et al. Low-dose prednisolone in addition to the initial disease-modifying antirheumatic drug in patients with early active rheumatoid arthritis reduces joint destruction and increases the remission rate: a two-year randomized trial. Arthritis Rheum 2005;52:3360-70. 
2. van der Heijde DM, van Leeuwen MA, van Riel PL, et al. Biannual radiographic assessments of hands and feet in a three-year prospective followup of patients with early rheumatoid arthritis. Arthritis Rheum 1992;35:26-34.

3. Prevoo ML, van't Hof MA, Kuper $\mathrm{HH}$, et al. Modified disease activity scores that include twenty-eight-joint counts. Development and validation in a prospective longitudinal study of patients with rheumatoid arthritis. Arthritis Rheum 1995;38:44-8.

4. Ekdahl C, Eberhardt K, Andersson SI, et al. Assessing disability in patients with rheumatoid arthritis. Use of a Swedish version of the Stanford Health Assessment Questionnaire. Scand J Rheumatol 1988;17:263-71.

5. Engvall IL, Svensson B, Tengstrand B, et al. Impact of low-dose prednisolone on bone synthesis and resorption in early rheumatoid arthritis: experiences from a two-year randomized study. Arthritis Res Ther 2008;10:R128.

6. Rantapää-Dahlqvist S, de Jong BA, Berglin E, et al. Antibodies against cyclic citrullinated peptide and IgA rheumatoid factor predict the development of rheumatoid arthritis. Arthritis Rheum 2003;48:2741-9.

7. van der Heijde DM, van Riel PL, van Leeuwen MA, et al. Prognostic factors for radiographic damage and physical disability in early rheumatoid arthritis. A prospective follow-up study of 147 patients. Br J Rheumatol 1992;31:519-25.

8. van der Helm-van Mil AH, Verpoort KN, Breedveld FC, et al. Antibodies to citrullinated proteins and differences in clinical progression of rheumatoid arthritis. Arthritis Res Ther 2005;7: R949-58.

9. Aletaha D, Alasti F, Smolen JS. Rheumatoid factor determines structural progression of rheumatoid arthritis dependent and independent of disease activity. Ann Rheum Dis 2013;72:875-80.

10. Engvall IL, Svensson B, Boonen A, et al. Low-dose prednisolone in early rheumatoid arthritis inhibits collagen type I degradation by matrix metalloproteinases as assessed by serum 1CTP_a possible mechanism for specific inhibition of radiological destruction. Rheumatology 2013;52:733-42.

11. Burmester GR, Feist $\mathrm{E}$, Kellner $\mathrm{H}$, et al. Effectiveness and safety of the interleukin 6-receptor antagonist tocilizumab after 4 and 24 weeks in patients with active rheumatoid arthritis: the first phase IIlb real-life study (TAMARA). Ann Rheum Dis 2011;70:755-9.

12. Soto L, Sabugo F, Catalan D, et al. The presence of anti-citrullinated protein antibodies (ACPA) does not affect the clinical response to adalimumab in a group of RA patients with the tumor necrosis factor (TNF) alpha-308 G/G promoter polymorphism. Clin Rheumatol 2011;30:391-5.

13. van den Broek M, Dirven $L$, Klarenbeek NB, et al. The association of treatment response and joint damage with ACPA-status in recent-onset RA: a subanalysis of the 8-year follow-up of the BeSt study. Ann Rheum Dis 2012;71:245-8.

14. de Vries-Bouwstra JK, Goekoop-Ruiterman YPM, Verpoort KN, et al. Progression of joint damage in early rheumatoid arthritis. Association with HLA-DRB1, rheumatoid factor, and anti-citrullinated protein antibodies in relation to different treatment strategies. Arthritis Rheum 2008;58:1293-8.

15. Barra L, Bykerk V, Pope JE, et al. Anticitrullinated protein antibodies and rheumatoid factor fluctuate in early inflammatory arthritis and do not predict clinical outcomes. J Rheumatol 2013;40:1259-67.

16. Guzian MC, Carrier N, Cossette $P$, et al. Outcomes in recent-onset inflammatory polyarthritis differ according to initial titers, persistence over time, and specificity of the autoantibodies. Arthritis Care Res 2010;62:1624-32.

17. Ursum J, Bos $\mathrm{WH}$, van Dillen $\mathrm{N}$, et al. Levels of anti-citrullinated protein antibodies and IgM rheumatoid factor are not associated with outcome in early arthritis patients: a cohort study. Arthritis Res Ther 2010;12:R8.

18. Bohler C, Radner H, Smolen JS, et al. Serological changes in the course of traditional and biological disease modifying therapy of rheumatoid arthritis. Ann Rheum Dis 2013;72:241-4. 